\title{
Explaining nurses' experiences of caring for brain dead patients: a content analysis
}

\author{
Hamideh Yazdi Moghaddam ${ }^{1,2}$, Zahra Sadat Manzari $^{3}$, Abbas Heydari ${ }^{4}$, Eesa Mohammadi ${ }^{5}$
}

${ }^{1}$ Ph.D. of Nursing, Faculty of Nursing and Midwifery, Mashhad University of Medical Sciences, Mashhad, Iran

2 Assistant Professor, Anesthesiology and Operating Room Department, Faculty of Paramedices, Sabzevar University of Medical Sciences, Sabzevar, Iran

${ }^{3}$ Ph.D. of Nursing, Assistant Professor, Department of Medical-Surgical Nursing, Faculty of Nursing and Midwifery, Mashhad University of Medical Sciences, Mashhad, Iran

${ }^{4}$ Ph.D. of Nursing, Professor, Evidence-Based Caring Research Center, Department of Medical-Surgical Nursing, Faculty of Nursing and Midwifery, Mashhad University of Medical Sciences, Mashhad, Iran

${ }^{5} \mathrm{Ph} . \mathrm{D}$. of Nursing, Professor, Department of Nursing, Faculty of Medical Sciences, Tarbiat Modares University, Tehran, Iran

\section{Type of article: Original}

\begin{abstract}
Background: Caring for patients with brain death diagnosis is the heaviest of duties for nurses, and, due to the complexities and stressors, it is the biggest challenge of nursing in an intensive care unit.

Objective: This qualitative research aimed to disclose the nurses' experience of caring for brain-dead patients.

Methods: The present study was a qualitative research using a content analysis, where the data collection process included 21 semi-structured and in-depth interviews with intensive care nurses, physicians, head nurses, a transplantation committee coordinator, and the authority of the organ procurement unit. Adequate data were collected from March 2014 until the saturation point was reached in June 2016. Data were analyzed simultaneously with data collection using qualitative content analysis with a conventional approach.

Results: Qualitative content analysis of data resulted in two themes and eight subthemes, reflecting the analysis of nurses' experiences of caring for brain-dead patients. The themes included "Challenges of right and duty requirement," and "turbulent confrontation with successive chains of tension". Finally, the main themes of "resonance of stress and internal conflict in care" were abstracted.

Conclusion: The findings deepened our understanding and knowledge of the issue. Despite all the stress, nurses care for potential organ donors, and this results in preserving the organs' viability for donation. Nurses' problems and challenges in this caring process should be considered by policymakers of health and treatment systems and a supportive model be designed for nurses in the intensive care unit.

Keywords: Brain dead; End of life care; Qualitative research
\end{abstract}

\section{Introduction}

Caring has been defined as a human characteristic, an interpersonal interaction, and a therapeutic intervention (1) and it has been attributed a special place in nursing literature (2). A major dimension of caring in nursing is the caring given to patients who are dying. Death is regarded as a major concept in nursing theories (3). Therefore, brain death is also regarded as a type of death (4). In the US, less than $1 \%$ of all deaths (about 15 to 20 thousand) are brain dead, and over 15,000 brain deaths occur annually $(5,6)$. According to the statistics available in Iran, the major

\section{Corresponding author:}

Assistant Professor Dr. Zahra Sadat Manzari, Department of Medical-Surgical Nursing, Faculty of Nursing and Midwifery, Mashhad University of Medical Sciences, Mashhad, Iran.

Tel:+98.5138598019, Fax:+98.5138597313, Email: Manzariz@mums.ac.ir

Received: September 27, 2017, Accepted: October 08, 2017, Published: August 2018

iThenticate screening: October 08, 2017, English editing: July 24, 2018, Quality control: July 25, 2018

This article has been reviewed / commented by four experts

Funding / research project approval: Mashhad University of Medical Sciences (Ref: 931512)

Ethics approval: Mashhad University of Medical Sciences (Ref: IR.MUMS.REC.1394.58)

(C) 2018 The Authors. This is an open access article under the terms of the Creative Commons Attribution-NonCommercialNoDerivs License, which permits use and distribution in any medium, provided the original work is properly cited, the use is non-commercial and no modifications or adaptations are made. 
cause of brain death in Iran is car accidents (7-9), such that in 2016, the death rate due to car accidents was 16000 deaths per year. Of these, 5000-8000 brain death were reported and 2500 to 4000 cases were identified as potential organ donors (10) who are cared for and supported by nurses in the ICU (11). The high rate of brain deaths indicates that ICU nurses mostly deal with brain-dead patients, since brain-dead patients are admitted to the ICU for the rest of their lives and nurses are assigned to care for them. Therefore, nurses' experience of caring for these patients and their families has attracted researchers' attention (12). One of the issues considered in caring for brain-dead patients is one of the hardest duties for nurses, which is caring for potential organs' viability for donation, such that nurses mention their experience of caring for brain-dead patients as a big challenge (13). The sensitivity of caring for these patients and their stressful position imposes lots of mental and psychological problems on nurses, since most brain dead patients are young and have died suddenly and unexpectedly $(14,15)$. Especially, when their family gives consent to donate organs of their brain-dead patient, caring for these patients as potential organ donors becomes the hardest responsibility of the ICU nurses and they have to explain to their families the changes that occur in caring for these patients. The level of activities and care at the patient's bedside increases with the direct attention to maintaining organ viability for donation (16). High involvement of nurses in the caring process along with the grief of the brain-dead patients' families can be a great source of stress and these emotional conflicts cause stress in nurses. Many nurses, when involved in the procurement process for organ donation, feel guilty because it conflicts with personal feelings and professionalism (17). The majority of nurses believe they do not have the training required to provide the correct care for organ donor patients (18). The probability of error and mistakes in managing the patient's caring process and endangering the viability of donated organs due to the lack of knowledge, add a lot of stress to nurses (19). The susceptibility of patients in the ICU, exposure to critical situations, and the high anxiety of relatives of patients while seeing their vulnerable loved ones, have made nursing to be considered as a complex care and the heaviest of duties for nurses in the ICU. This challenge affects nurses' performance in caring for patients in the whole process due to the increased workload, priority and sensitivity of caring in the ICU (20). Therefore, considering the stressful factors of caring for brain-dead patients is important for nurses (1), since accurate and comprehensive recognition of challenges of caring for brain dead patients from the nurses' point of view, will be of great importance in providing holistic and quality care $(21,22)$.

Researchers have found that considering nurses' experiences and employing them will provide more knowledge to facilitate the caring for these patients (23). However, with regard to the sensitivity of the ICU and the need for total care for brain-dead patients that includes both caring for patient and interaction with other members of the medical team (the physician and donation team) and even the patient's family, nurses' experiences of caring for brain-dead patients are less considered. Considering these stressful conditions in the process of caring for the brain dead, nurses are asked to intervene correctly, to be in contact with patients' families and support them. Therefore, expecting the correct intervention of nurses in this challenging issue will not certainly be successful. In order to achieve such a goal, nurses' real experiences in this difficult situation should be taken into account. Another reason for the appropriateness of a qualitative research method to examine this type of phenomenon is that selecting the study method depends on the phenomenon under study (24), and caring is a multidimensional phenomenon, where social and cultural grounds play major roles. In other words, qualitative research is a mental and systematic method used to describe life experiences and to obtain their meaning (25). Advocates of the qualitative approach also believe that in situations where the subject is not well defined and the range and sequence of activities involved with the subject under study is unknown, to understand it better and deeper, special methods are required to identify its different dimensions clearly and comprehensively, and, in such cases, qualitative methods are significantly effective and efficient (26). The aim of this study was to discover the mental world of nurses' experience of caring for brain-dead patients could be investigated and a major step could be taken in this regard.

\section{Material and Methods}

\subsection{Study design and participants}

The paradigm and philosophical foundation of this study is the naturalistic paradigm. Naturalistic methods seek to explain people's complexities. Naturalistic studies lead to deep information that could clarify various dimensions of complex human phenomena (26). The research method derived from naturalistic paradigm is the qualitative method (27). Indeed, this study was a qualitative content analysis of conventional type, which was to make sense of qualitative data through their reduction and categorization (28).

\subsection{Interview and data collection}

Purposive sampling was conducted from March 2014 to June 2016, and participants were recruited among nurses working in hospitals affiliated with universities of medical sciences in Mashhad, Neishabour and Sabzevar. The 
inclusion criteria were nurses with bachelor's degrees, at least one-year working experience in the ICUs, a history of caring for brain-dead patients, no history of depression or psychiatric illnesses, and a willingness to participate in the study and describe their caring experiences. Sampling continued until data saturation i.e. no new conceptual codes were obtained from the new interviews (28). Data saturation occurred after interviewing with eighteen participants, but three more interviews were conducted for assurance (aggregate twenty-one). We employed a semi-structured inperson interview accompanied by field notes for data collection. We used general open-ended questions, such as "How did you feel when you were assigned to care for a brain dead patient for the first time?", "Could you please explain each caring situation accurately and in detail?", "How did you feel in each situation?", and "What challenges and problems did you encounter?" All the interviews were conducted by the first author in a quiet, private room located in each hospital. The researcher's skill in the interview was helpful due to the experience of conducting previous interviews, the ability of abstract thinking and critical analysis of achieved opportunities as well as the experience of conducting qualitative research. Each interview session took about 40-95 minutes based on the tolerance of the participants. We recorded the interviews using a digital sound recorder. Data collection continued until data saturation, and a rich description of the nurses' experiences and perspectives was obtained.

\subsection{Ethical considerations}

This study was approved by the Ethics Committee of Mashhad University of Medical Sciences (Ref: IR.MUMS.REC.1394.58). A written informed consent was obtained from participants, following brief explanations and clarifications of the research and its objectives. They were all assured of data confidentiality, their voluntary participation, and the right to withdraw from the study at any point was given without any question. In order to record the participants' statements, permissions were taken.

\subsection{Data Analysis}

Data analysis was performed through qualitative content analysis of conventional type. Content analysis is well suited to analyze the multifaceted, important, and sensitive phenomena of nursing. If conducting exploratory work in an area where little is known, content analysis may be suitable for the simple reporting of common issues mentioned in data. In this approach, the production of the themes is derived in an inductive way, directly from the study data (29). Each interview was immediately transcribed on the same day along with participants' non-verbal communications such as cries, smiles, silence. The transcription of every interview was repeatedly read for achieve immersion and to get a sense of the whole. Then, transcriptions were studied word by word to find key thoughts and concepts, and they were marked. Units were coded using the exact words from the text, or the words or statements made according to the researcher's impression. Semantic units were also reviewed several times and the codes appropriate to each semantic unit were written. Afterward, conceptually similar codes were located in a cluster, which was more general and conceptual, and finally, the categories (themes) were abstracted. Next, according to the codes and clusters in each theme, subthemes (subcategories) were identified. The analysis process was repeated with more interviews and the categories were corrected in this respect (30). With the development of the main themes, definitions for the themes and subthemes were established, and exemplars for each code and theme were identified from data in order to report the findings.

\subsection{Data Trustworthiness}

Data trustworthiness was achieved using the Lincoln and Guba criteria $(30,31)$. In order to achieve credibility, we employed a member-checking technique. To this purpose, transcripts, interviews, and units of analysis along with initially extracted codes were presented to participants to obtain their confirmation and complimentary comments. In addition, interviews, initial codes, and themes were reviewed by a co-researcher and two professors in the field of qualitative research. Sampling with maximum variance, i.e. interviews with different individuals (in terms of age, gender, employment status, working experience, and workplace), verified the data transferability. Attributing enough time to the study and having open relationships with participants were factors that increased the credibility of data in the present study. The creditability of the results was also determined through numerous and long-term reviews and analysis lasting throughout the year.

\section{Results}

Totally, twenty-one subjects participated: nurses, head nurses, staff nurses, a transplantation committee coordinator, and the authority of the organ procurement unit. Participants were ten females and eight males, with the age range of 28-50 years with 2-17 years of working experience. Themes and subthemes derived from the participants' perspectives and experiences are described as follows (Table 1). Data analyses lead to the emergence of two themes, eight categories, thirty-three subcategories and one thousand two hundred and thirty-seven $(1,237)$ initial codes. 
Themes included "challenge of the right and duty requirement" and "turbulent confrontation with successive chains of stress" and the theme abstracted from these themes was called "resonance of stress and internal conflict in care" as the final theme.

Table 1. List of themes and categories for the central theme of "Resonance of stress and internal conflict in care"

\begin{tabular}{|c|c|c|}
\hline Theme & Category & Subcategory \\
\hline \multirow[t]{13}{*}{$\begin{array}{l}\text { Challenge of right } \\
\text { and duty requirement }\end{array}$} & \multirow{4}{*}{$\begin{array}{l}\text { Stress of preserving } \\
\text { patients' viability for } \\
\text { donation. }\end{array}$} & $\begin{array}{l}\text { Stressful caring due to the importance of preserving organ viability } \\
\text { for donation }\end{array}$ \\
\hline & & $\begin{array}{l}\text { Complexity and difficulty of comprehensive caring for organ- } \\
\text { donor patient }\end{array}$ \\
\hline & & Care-oriented efforts to achieve donation objectives \\
\hline & & Stress of preserving patients' viability \\
\hline & \multirow{9}{*}{$\begin{array}{l}\text { Feelings of guilt and } \\
\text { negligence }\end{array}$} & Accuracy and sensitivity in care due to fear of negligence \\
\hline & & $\begin{array}{l}\text { Unpleasant perception of brain death following negligence in } \\
\text { caring }\end{array}$ \\
\hline & & $\begin{array}{l}\text { Mental involvement due to recording the care that were not } \\
\text { provided for non-organ donors }\end{array}$ \\
\hline & & Attention and sensitivity in caring due to the Feelings of guilt \\
\hline & & $\begin{array}{l}\text { Mental conflict of the brain death occurring due to negligence in } \\
\text { care }\end{array}$ \\
\hline & & $\begin{array}{l}\text { Fear of negligence in caring to preserve patients' viability for } \\
\text { donation }\end{array}$ \\
\hline & & $\begin{array}{l}\text { Psychological effects following negligence in caring for non- } \\
\text { organ-donor patients }\end{array}$ \\
\hline & & $\begin{array}{l}\text { Conscience following negligence in caring for a non-organ-donor } \\
\text { patient }\end{array}$ \\
\hline & & $\begin{array}{l}\text { Stressful caring, following mental conflict due to negligence in } \\
\text { caring }\end{array}$ \\
\hline \multirow{20}{*}{$\begin{array}{l}\text { Turbulent } \\
\text { confrontation with } \\
\text { successive chains of } \\
\text { tension }\end{array}$} & \multirow{4}{*}{$\begin{array}{l}\text { The stress of declaring } \\
\text { brain death to the } \\
\text { family }\end{array}$} & Declaring brain death being difficult and unpleasant \\
\hline & & Reluctance to declare brain death \\
\hline & & $\begin{array}{l}\text { Preferring brain death to be declared by the nurses of the transplant } \\
\text { committee }\end{array}$ \\
\hline & & Preferring brain death to be declared by a physician \\
\hline & \multirow{2}{*}{$\begin{array}{l}\text { Stressful experience of } \\
\text { the first caring }\end{array}$} & Stress of the first exposure \\
\hline & & Difficulty and stressful experience of the first caring \\
\hline & \multirow{5}{*}{$\begin{array}{l}\text { Difficulty of } \\
\text { confronting the } \\
\text { families' feelings }\end{array}$} & Difficulty of confronting the families' feelings \\
\hline & & Painful farewell of the family of the patient \\
\hline & & Difficulty of encountering due to the family's misunderstanding \\
\hline & & $\begin{array}{l}\text { Sorrow of the family's mental conception of donation as their loved } \\
\text { ones being cut into pieces }\end{array}$ \\
\hline & & Sorrow and despair due to sympathizing with families \\
\hline & \multirow{3}{*}{$\begin{array}{l}\text { Sense of lacking } \\
\text { support in caring }\end{array}$} & Fear of possible complaints despite correct caring \\
\hline & & Sorrow due to the lack of support by the medical and caring system \\
\hline & & Unpleasant feeling of being neglected \\
\hline & \multirow[t]{3}{*}{$\begin{array}{l}\text { Stress of being blamed } \\
\text { by the family }\end{array}$} & $\begin{array}{l}\text { Sorrow and mental engagement due to the negative reaction of } \\
\text { families }\end{array}$ \\
\hline & & Feeling of insecurity, and fear of violent reaction of the family \\
\hline & & Difficulty of being blamed by the family \\
\hline & \multirow{3}{*}{$\begin{array}{l}\text { Despair and } \\
\text { disappointment after } \\
\text { confirmation of brain } \\
\text { death }\end{array}$} & Despair and grief after confirmation of brain death \\
\hline & & Reluctance in providing care due to hopelessness \\
\hline & & $\begin{array}{l}\text { Sorrow and despair of caring attempts being fruitless before brain } \\
\text { death event }\end{array}$ \\
\hline
\end{tabular}




\subsection{Theme I: Challenge of right and duty requirement}

Upon accepting the care for potential donor patients, nurses make all efforts to preserve organ viability until the consent of the family for donation is obtained and the donation process is completed. In fact, throughout the caring process of brain-dead patients, there is always a requirement for a nurse to preserve the potential organ donors' viability. On the one hand, some brain-dead patients are not considered as organ donors due to conditions such as the lack of consent of their family or the patient's conditions, and, in cases of failing to care for these patients, some nurses will suffer from the mental conflict of negligence. Indeed, it is an expression of obligation to (patient) right in taking care of them. This theme is composed of the following two major categories:

\subsubsection{The stress of preserving patients' viability for donation}

This category consists of 4 subcategories (Table 1) which shows that when caring for an organ donor patient, nurses face some concerns, including preserving the patients and organs' viability for donation. These concerns add to the difficulty of caring for these potential organ donors, concurrent with the sensitivity of caring due to their vulnerable conditions. On the other hand, with regard to all these sensitivities, nurses also encounter the fear of losing patients. One of the participants with eight years' experience of working in the ICU and caring for brain-dead patients stated, "... If the patients are potential organ donors, we try to continue caring more accurately with more sensitivity to preserve them for donation and to preserve the intended organ viability" (P3). As the major concern of most nurses, caring for brain-dead patients, especially potential organ donors, is the stress of the viability of the patients and reaching the transplant center. Another participant with thirteen years' experience of working in the ICU and caring for brain-dead patients stated, "... I was concerned about my brain-dead patients' survival, especially their organs to be donated to those who need them. Therefore, it is very difficult to care for them because of the high sensitivity..." (P5). Most nurses repeatedly mentioned the stress of caring for patients and preserving their viability for donation. A participant with seventeen years' experience of working in the ICU, and caring for brain-dead patients stated, "... Patients who are potential organ donors make the task more demanding, considering their viability. You see the patient has tachycardia, their blood pressure falls etc. you should be very careful ..." (P7).

3.1.2. Feelings of guilt and negligence

This category consists of 9 subcategories (Table 1) and it expresses that despite caring for brain-dead patients, nurses suffer from concerns like the Feelings of guilt and negligence, such that in a case of potential organ donors, they are concerned with the fear of negligence due to the death of organ donors. In cases of non-organ donors, they also feel guilty of negligence in caring for them; especially, if the nurse feels that brain death has been the result of failure in caring for the patient due to the lack of knowledge and experience, they will suffer from a feeling of extortion in caring and Feelings of guilt following it. A participant with eleven years' experience of working in the ICU and caring for brain-dead patients stated, "... It does not mean that we are neglectful; somebody has been neglectful before that has made the patient worse. Before the patient is brain dead, you do not conduct a suction and they become hypoxic. You do not understand, it is too late for CPR and this is negligence, right? ....and then, you feel guilty..." (P1). In cases of caring for a brain-dead patient, sometimes, due to the lack of knowledge, nurses feel that they have neglected the patient and caring has not been conducted well; therefore, they suffer from the sense of Feelings of guilt and negligence. A participant with nine years' experience of working in the ICU and caring for brain-dead patients stated, "... I don't feel it is my negligence. I mean, maybe I can't do something due to the lack of knowledge and this is considered as negligence too. Sometimes I'm afraid not to make excuses for the patient because of the lack of knowledge ..." (P2). In caring for non-organ donors, nurses encounter some problems, because in cases of dividing tasks, caring for non-organ donors is concurrent with other patients who need much caring, and feel seriously ill. This causes nurses to fail in caring for these patients. A participant with ten years' experience of working in the ICU and caring for brain-dead patients stated, "... When they ask you to care for a nonorgan-donor patient and a patient who needs much care, you really don't know how to conduct the caring for both. Right, the non-organ donor is not going to go for transplant. But, sometimes the other patient needs so much care that you cannot provide caring for the brain-dead patient. This has happened to me. Then, I considered that they are human too and they have the right to be cared for. But the conditions were such that I could not provide the caring ..." (P11). According to the nurses, caring for non-organ-donor patients is considered as futile and useless from the physicians and the medical system's viewpoint. This is why nurses feel guilty in cases of not providing care, not giving the medication or even failure in doing CPR for a non-organ-donor patient. A participant with four years' experience of working in the ICU and caring for brain dead patients stated, "... Sometimes they say, do not resuscitate them, because they are non-organ donors. This is always very difficult for me. You know, when they say, "Leave them alone, let them go!", I could never get along with this and do nothing for a patient who is not a potential organ donor, I feel guilty ..." (P6). 


\subsection{Theme II: Turbulent confrontation with successive chains of stress}

The process of caring for a brain dead patient is considered as continuously facing various stressors, such that they have to encounter all these factors and manage them in addition to the stress of caring for the patient. This theme is composed of the following categories:

\subsubsection{Despair and disappointment after confirmation of brain death}

This category consists of three subcategories (Table 1) and it states that after confirming brain death, nurses face a feeling of grief and they are greatly influenced by the feeling of frustration of the patient's recovery and reassurance. A participant with eight years' experience of working in the ICU and caring for brain dead patients stated, "... When, for definite brain death patients they say that the patient will not survive, and they will expire in a case of not donating their organs, you think about why they became brain dead. You become disappointed, because now, you are sure that they will not come back ..." (P3). A participant with thirteen years' experience of working in the ICU and caring for brain-dead patients stated, "... For the work that you do for the patient and knowing that they will expire, your work seems fruitless, from this point of view, I said. Because they won't recover and you become disappointed that they won't come back ..." (P5).

\subsubsection{Difficulty of declaring brain death to the family}

This category consists of 4 subcategories (Table 1) and it states that the most difficult stage of caring for a braindead patient is to declare the bad news of brain death to their families, especially when the patient is introduced as a potential organ donor, the difficulty and stress of declaring brain death to the family is felt more. Declaring brain death is very hard and unpleasant for nurses and they do not like to declare it. They prefer brain death to be declared by the physician, or the authority of organ procurement unit to remove the burden of this responsibility from nurses. However, nurses are not responsible for declaring brain death. However, depending on the conditions and situation of various hospitals, especially the continuous presence of nurses at the patient's bedside and the frequent contacts made by their families, this difficult and stressful task is made a burden for nurses. A participant with nine years' experience of working in the ICU and caring for brain dead-patients stated, "... I do not feel good enough to announce this, because losing a beloved one is not good and it is very hard to tell someone about their beloved ones' death ..." (P2). Declaring brain death to the families is hard because families expect their patient to improve, and, if nurses convey the bad news and say that their loved one will not survive, it is very difficult. A participant with ten years' experience of working in the ICU and caring for brain-dead patients stated, "... It is very difficult to give this bad news to a family who are waiting to hear about their patient's improvement. They expect you to say that their patient is going to be fine. But now, you have to say, "Your patient is brain dead and there is no hope for his recovery" ..." (P4). Declaring brain death is hard and unpleasant and makes nurses unwilling to notify it to the families and to avoid it. A participant with twelve years' experience of working in the ICU and caring for brain-dead patients stated, "... I don't like it. It's not good. I believe this is the worst news you can deliver to someone. I try to avoid it, if it is my shift, and ask another nurse to do it ..." (P9).

\subsubsection{Stressful experience of the first caring}

This category consists of two subcategories (Table 1) and it shows that when nurses accept caring for a braindead patient for the first time, they face the stressful experience of first caring. In this situation, whether for an experienced or a novice nurse, there is the stress of the first caring of these patients, which can lead to the difficulty and stress of the first caring experience. A participant with seven years' experience of working in the ICU and caring for brain dead patients stated, "... It was very hard to confront my patient; I was very stressed out because it was my first time. Definitely, it is stressful for every nurse ..." (P8). In this regard, another participant stated, "... Brain-dead patients impose too much stress. Saving the patient and preserving them, avoiding their arrest... These are very important. Therefore, one might experience stress for the first time ..." (P16).

\subsubsection{Stress of being blamed by the family}

This category consists of three subcategories (Table 1) and it shows that when the patient experiences brain death after being admitted to the ICU, their family, the medical and caring system, particularly nurses, are blamed for it. Therefore, the stress of being blamed by patients' families creates caring stress in nurses. A participant with four years' experience of working in the ICU and caring for brain dead patients stated, "... Their patient is brain dead and the family blames you. You cannot remove this burden and explain it, it's very hard ..." (P10). In such conditions, they even treat nurses badly and negatively, such that nurses feel remorseful due to this negative reaction of the families. This makes the caring nurses sad and it affects their mental peace during the caring process. According to one of the participants, "... Sometimes their hurtful comments affect us. I am also a human and I may lose focus on caring following these reactions, when watching ventilation, giving medications on time. It psychologically distracts me ..." (P16). 


\subsubsection{Difficulty of confronting families' feelings}

This category consists of 5 subcategories (Table 1) and it explains another stressful situation; since, confronting families and watching their feelings towards their patients is very hard and unpleasant. A participant with five years' experience of working in the ICU and caring for brain dead patients stated, "... There was a young girl, and her family was very emotional. I could not help crying. There was a lump in my throat and I wanted to sob. You won't believe how hard it is to see such scenes, not just for me, but for all nurses..." (P13). In such stressful situations, some nurses could not communicate with families or even confront their harmful feelings, due to the intensified emotional feelings while sympathizing with the families. "The moment when families realize their patient is brain dead and they come to see him, it's a very painful scene. Families show intense reactions, I can't control myself, because I can't bear it. Sometimes I cry with them ..." (P12). When families of organ-donor patients come to say farewell, observing such scenes is very hard and painful for nurses. "... If I am in a farewell moment, I can't help crying. When you see their parents come to say farewell, when they cry, I leave. I can't get along with such scenes. When I remember them saying farewell while they are sad, I feel a lump in my throat..." (P14).

\subsubsection{The sense of lacking support in caring}

This category consists of 5 subcategories (Table 1) and it states that despite all stresses borne when caring for braindead patients, nurses feel they are not supported by the medical system and it adds to their caring stress. A participant with eight years' experience of working in the ICU and caring for brain dead patients stated, "... Even when a relative slaps you in the face and says that it was your fault our patient is brain dead, while the nurse is not guilty, authorities won't say anything. Even, despite the fact that nurses do their job correctly, there is concern on the likelihood of a lawsuit for them. According to one of the participants, "... We should keep the patients' records for two years so that you will not be legally prosecuted later, and in case you do not remember what you did and you become legally accused ..." (P17). These issues have made nurses feel their attempts in caring are neglected by both families and the medical system. A participant with seven years' experience of working in the ICU and caring for brain-dead patients stated, "... They never say it was the doctors' fault. They always say it is the nurses' fault that the patient is brain dead, the same nurse who is crying on the patients' bedside and nobody sees them ..." (P8). Another participant with fourteen years' experience of working in the ICU and caring for brain dead patients stated, "... The worst thing is that nobody sees us, but when a patient is brain dead or dies, it is our fault and this mentally distracts us and is very hard ..." (P15)

\section{Discussion}

The aim of this study was to explore the nurses' experiences of caring for brain dead patients. Results suggested that "resonance of stress and internal conflict in caring" is the most effective concept that shows nurses' experiences of caring for brain-dead patients, and, it is considered as the central theme covering all other themes of this study. Confronting growing stress and conflicts is the result of the abstraction of two concepts, including "the challenges of right and duty requirement" and "turbulent confrontation with successive chains of tension." In a review of the studies conducted, it was specified that although details and dimensions of the main themes of the study were pointed out sparsely, the general theme of most categories formed in this study complies with the results of other studies $(4,12,16,32-36)$. However, in those studies, only the stress of preserving the patients' viability for donation was addressed and none of them have addressed nurses' experiences of caring for brain-dead patients as non-organ donors, and the related challenges.

\subsection{Challenge of right and duty requirement}

According to the current study, challenge of right and duty requirement is the most important stressor for nurses caring for brain dead patients.

\subsubsection{Stress to preserve organ-donor patients' viability}

One of the concepts that appeared in the present study is the stress to preserve organ donor patients' viability. In a study by Salehi et al., the main theme was "excruciating tasks" and this theme was formed as the main theme by mental and psychological effects of confronting such a situation, and heavy and stressful care. The category of heavy and stressful care consists of features such as preserving organ-donor patients' viability, the process of preparing donation organs, hard and intense caring, and the stressful caring process. In another study, nurses stated that caring for organ donor patients has been a very stressful and hard experience for them to preserve organ viability for donation, and, it could be considered as a threat for nurses' health and the quality of nursing care. Therefore, nurses mention the experience of caring for brain dead patients as a big challenge (32). In the present study, the category of "confronting growing stresses and conflicts" complies with the main theme of "excruciating tasks" in this study. In addition, the category of "heavy and stressful care" in this study complies with the category of "the stress of preserving patients' viability for donation" in our study, which could be due to the similarities in 
caring structures of the two studies for nurses after caring for brain-dead patients that makes them suffer such stress. Results of an Australian study by Pearson showed that confronting the care for the potential organ donor is the hardest duty for nurses in the ICU and it intensely requires nurses to find a meaning for that event, such that they have to explain changes in caring for the patient to families in addition to the stress of caring (16). Forsberg in Sweden suggested that when the patient is brain dead, intense and stressful nursing and technical interventions are required, to preserve patients' organ viability for donation (33). A study in 2000 by Sadala showed that the major concern of nurses in caring for organ donors is to preserve their physiologic function to organ viability for later use (34). Concepts of this study comply with the concept of "the necessity to preserve organ donor patients' viability" in the present study. Our findings were different from that study in terms of caring structure and the medical environment of the ICU; but, regardless of the context and structure, nurses try to preserve patients' organ viability for donation. In both studies, the usefulness of the organs for recipients is considered by nurses. In 2004, CarterGentry showed the importance of caring for organ donor patients as the most essential aspect of nursing care for patients before going to the operation room for donation (37).

4.1.2. Fear of negligence in caring for organ donor patients

One of concepts that appeared in this study was the fear of negligence in caring for organ-donor patients. Hibbert realized that there are three sources of stress for nurses when caring for brain dead patients (38). These sources of stress include lack of time to interact with family members, the stress of making mistakes in managing the caring process of donor patients and therefore, endangering the viability of potential organs for donation, and emotional requirements of the family members (38). The study by Pelletier-Hibbert in Canada demonstrated that when a braindead patient is admitted to the ward, nurses confront three major stresses, including the fear of losing the donor patient, lack of time to fulfill information and supporting needs of the family, and uncertainty in prescriptions of some physicians (39). Concepts of these studies comply with "the fear of negligence" in our study. In both studies, nurses expressed the fear of negligence in caring to preserve patients' viability for donation. However, the fear of failure in the study by Pelletier- Hibbert is not due to the lack of knowledge. Rather, it is due to the short time that organs have to survive, and this short time creates stress and fear in nurses in preventing mistakes in the caring process. However, in our study, this fear of negligence in most nurses was due to the lack of knowledge and awareness in caring for brain-dead patients. The study by Collins in the UK showed that the majority of nurses believe they are not well prepared to provide care for organ-donor patients (18). This adds to the caring stress following the mental conflict of negligence.

\subsection{Turbulent confrontation with successive chains of caring stress}

The most important stressor for nurses caring for brain dead patients is "turbulent confrontation with successive chains of caring stress."

\subsubsection{Despair and disappointment after confirmation of brain death}

Another concept of the study is "despair and disappointment after confirmation of brain death." The healthcare team, and particularly nurses, were affected by uncertainties and ambiguities originated from the care for brain-dead patients. Another study showed that uncertainties and discrepancies between physicians and nurses in terms of understanding were obvious in the process of the disconnection of the patient from the vital devices (35). It should be noted that most nursing systems have reached such uncertainties in different fields, although, such communities have been different in terms of religion and culture. However, such uncertainties about diagnosis are still obvious, and it causes disappointment and distrust to confirm brain death. Therefore, nurses in intensive care units should have a clear understanding of the concept of brain death in order to be able to take care of brain-dead patients by avoiding psychological effects (40).

4.2.2. The stress of declaring brain death to the family

Another stressor in this study was the concept of "the stress of declaring brain death to the family." Results of the study by Floden, demonstrated that this is considered as a challenging issue for nurses during the caring process due to their ongoing presence in the ward and the families' access to them, which is very problematic and stressful (41), since nursing care is not limited to patients, rather, it includes encountering special needs of the patients' families who are in crisis and are passing these acute and stressful clinical conditions. Coyle realized that in caring for patients and their families, nurses should understand issues related to the diagnosis of brain death and be aware of them (21) to give correct information on the patients' conditions to their families. However, since families are not adeptly aware of brain death (41), this exacerbates the stress of declaring brain death to the families by nurses (21). Therefore, most nurses are reluctant to announce the bad news and prefer the physician or the authority of the transplant unit do this. In the study by Long in the US, conducted on families' adaptation with brain death, the category of "announcing the bad news" appeared (42). 


\subsubsection{Stressful experience of the first caring}

According to the results of this study, one of the stressors in this field is the concept of "stressful experience of first caring." Caring for brain-dead patients for the first time brings much stress for nurses, since conditions of these patients, especially organ donors, are such that the patient should be preserved for donation, and this creates much stress for nurses, especially when they are caring for brain dead patients for the first time. The study by Salehi et al. showed that the spiritual perceptions experienced by the participants have been more in the first confrontation with these patients, and it has diminished gradually by frequent confrontation with them (32).

4.2.4. Confronting the stress of being blamed by the family

"Confronting the stress of being blamed by the family" as one of the concepts of this study, plays a major role in the stress and tension of nurses caring for brain-dead patients. Studies have shown that nurses face a lot of pressure in caring for brain dead-patients and interacting with their families in the process related to the diagnostic information of brain death and other requirements, since, they should also be accountable for the major questions asked by the families (36). Since most brain-dead patients are young and they have suddenly become brain dead, it is very difficult to provide care for them considering their stressful conditions, for both nurses and families, and they face many mental and psychological issues $(14,15)$. Results have shown that this high involvement of nurses in the caring process along with sadness of brain-dead patients' families could create a great source of stress for nurses (17). Admitting brain death is very difficult for most of the families, and following the request of the medical system for organ donation and the stress resulted from it, families consider nurses as guilty for their loved ones' brain death and this creates much stress for the caring nurses.

\subsubsection{The difficulty of confronting family emotions}

Another concept of the study is "the difficulty of confronting family emotions." Since most brain-dead patients have suddenly experienced this situation, families have not had the time to adapt to this and accept their patients' brain death. Therefore, it is very difficult for them to face this reality (15) and it can play a major role in the stress and tension of nurses caring for a brain-dead patient. Confronting the diagnosis of brain death for families, means entering a space full of challenges, contrasts and ambiguities, and it becomes more complicated by the emergence of sorrowful emotions and sometimes, psychological defensive reactions (43). Due to the emotional conditions of the family, it is very difficult for nurses to communicate and sympathize with them and it accompanies emotional reactions (33). Concepts of this study comply with the concept of difficulty in confronting families' feelings in our study. In the study by Sadala, the theme of nurses' relations with others includes nurses' emotions, nursing identity in relation with the patient, nurses' relation with the health team, families' understanding, and guiding the family. However, nurses' experiences showed that it is difficult for them to communicate with family members, since nurses' views towards patients as organ donors are as regards to a person, and therefore, it is very painful for them to confront families' sorrows and grief as they lose their patient (34). Concepts of this study comply with the concept of confronting families' feelings in our study. This shows that regardless of the context, it is difficult for every nurse in any culture or country to confront painful feelings of families of brain-dead patients. In his study, following the study of nurses' experiences of caring for organ donor patients, Pearson realized that nurses' experiences of confronting emotions of families following the attempts made to support and sympathize with them have been painful, considering the emotional demands (16). Salehi et al. realized that confronting emotional effects of families of donors was painful, and it seemed that some nurses are not sufficiently ready to face these reactions (32). Therefore, facing critical conditions and high anxiety of families as they see the vulnerable situation of their loved ones', has made nursing care a complex phenomenon as the heaviest responsibility of ICU nurses (20).

\subsubsection{The sense of lacking support in caring}

The concept of "the sense of lacking support in caring" was identified in this study. However, in other studies, it has not been considered as an independent and contextual theme. In the following studies however, the importance of supporting nurses when caring for brain dead patients has been considered. Results of the study by Floden showed that nurses reported their lack of being supported by their seniors when caring for organ donor patients (41). The study by Smith in Australia showed that nurses should be aware that in this stressful situation, their colleagues and they themselves might also need support (44). Results of the study by Karimi showed that nurses experience serious problems when confronting dying patients. They need organizational support to adapt to these problems, and neglecting their demands will pose unwanted effects on them, and care from their patients (45). Nurses have a key role in taking care of brain dead patients in a health care team, means and methods on how to remove these challenges should be instigated (40). Results demonstrated that the supportive conditions of the work place affect nurses' ability to employ their knowledge and skills at work. Therefore, it seems necessary to make plans in line with supportive conditions of the workplace to improve the quality of caring and nurses' productivity (46). 


\subsection{Study limitations}

A limitation of this study is that the only participants were nurses working at hospitals affiliated with the University of Medical Sciences in three cities of Khorasan Razavi province who were willing to be interviewed, and it does not cover nurses of other hospitals and cities who have the experience of caring for brain-dead patients.

\section{Conclusions}

Results of the study showed that nurses still face many caring challenges in this domain, and since they play an axial role in caring for brain-dead patients in the medical team, ignoring these demands could affect the quality of caring for these patients. Therefore, it is recommended to the educational system of universities and medical centers to provide training and supportive plans for the process of caring for brain-dead patients and organ donation in all dimensions, to increase the knowledge in this regard by considering nurses' psychological and emotional demands. Given the importance of quality and accuracy in caring for brain-dead patients to preserve their organs' viability for donation, as well as issues raised on the emotional and mental experiences of nurses, these findings are practically important in increasing the quality of caring for brain-dead organ-donor patients as well as their vital organs' viability in the process of donating potential organs. On the other hand, the nursing system could pay more attention to nurses' demands in this process, and considering the space and conditions, the required planning should be made to improve the quality of nursing care as well as to provide required support for nurses in this regard.

\section{Acknowledgments:}

The authors hereby express their heartfelt gratitude to all participants of this study who patiently recounted and provided their experiences to be implemented in the research. This study was a part of a doctoral dissertation approved by the Faculty of Nursing and Midwifery at Mashhad University of Medical Sciences (Ref: 931512). This research was supported and funded by Mashhad University of Medical Sciences, Mashhad, Iran.

\section{Conflict of Interest:}

There is no conflict of interest to be declared.

Authors' contributions:

All authors contributed to this project and article equally. All authors read and approved the final manuscript.

\section{References:}

1) Meleis AI. Theoretical Nursing Development\& Progress. Philadelphia: Lippincott Williams and Wilkins; 2012.

2) Nikfarid L, Rasouli M. Caring curriculum: a new paradigm in nursing education. Iran Journal OF Nursing (IJN). 2011; 24(70): 61-71.

3) Motevalizade S, Zakyaei Sh. Brain death. J Gorgan Uni Med Sci. 2007; 9(2): 5-6.

4) Bosnell R, Madder H. Concepts of brain death. Surgery. 2011; 29(7): 289-94. doi: 10.1016/j.mpsur.2011.04.001.

5) Understanding Death Before Donation. 2014. Available from: http://www.organtransplants.org/understanding/death/.

6) Zohoor AL, Piri Z. Attitudes of Physicians and Nurses of intensive care unit to organ Transplantation with Brain Dead in Hospitals Affiliated with Iran university of Medical Sciences Tehran 2003. RJMS. 2004; 11(39): 97-105.

7) Ghadipasha M, Nikian Y, Salehi M, Tajaddini Z. The study of physican attitude concerning organ donation and the level of information about laws \& sanctions and the procedure in brain death. SJFM. 2008; 14(2): $112-6$.

8) Abbasi Z, Peyman A. Evaluation of brain death and organ transplantation in Iran Medical Law. 2012; 6(20): 43-54.

9) Amar from brain death and organ transplantation in Iran. 2013. Available from: http://www.asriran.com/fa/news/263264. 2013.

10) Organ donation and organ transplantation Statistics in iran and the world. Available from: https://ehdacenter/en/show-post/statistics/

11) Ghods AJ. Current status of organ transplant in Islamic countries. Exp Clin Transplant. 2015; 13(1): 13-7.

12) Ronayne C. A phenomenological study to understand the experiences of nurses with regard to brainstem death. Intensive Crit Care Nurs. 2009; 25(2): 90-8. doi: 10.1016/j.iccn.2008.06.001. PMID: 18657425. 
13) Frid I, Bergbom-Engberg I, Haljamäe H. Brain death in ICUs and associated nursing care challenges concerning patients and families. Intensive Crit Care Nurs. 1998; 14(1): 21-9. doi: 10.1016/S09643397(98)80071-2.

14) Abbasi Dolatabadi Z, Farahani B, Fesharaki M, Najafizadeh K. Effect of education about brain death and organ donation on attitude and knowledge of nursing students. Iranian Journal of Critical Care Nursing. 2010; 3(3): 109-12.

15) Williams M, Morton J, Peters S. The end-of-life care experiences of relatives of brain dead intensive care patients. Journal of pain and symptom management. 2008; 37(4): 659-64. doi: 10.1016/j.jpainsymman.2008.04.013. PMID: 18789640.

16) Pearson A, Robertson-Malt S, Walsh K, Fitzgerald M. Intensive care nurses' experiences of caring for brain dead organ donor patients. J Clin Nurs. 2001; 10(1): 132-9. doi: 10.1046/j.1365-2702.2001.00447.x. PMID: 11820230.

17) Kima J.R, Elliotta D, Hyde C. Korean health professionals' attitudes and knowledge toward organ donation and transplantation. International Journal of Nursing Studies. 2004; 41: 299-307. doi: 10.1016/j.ijnurstu.2003.10.003. PMID: 14967187.

18) Collins TJ. Organ and tissue donation: a survey of nurse's knowledge and educational needs in an adult ITU. Intensive and critical care nursing. 2005; 21(4): 226-33. doi: 10.1016/j.iccn.2004.10.006. PMID: 16039960.

19) Yazdimoghaddam H, Manzari ZS. Training; a golden ring for removing nurses' challenges in caring process of the brain death patients. Hayat. 2017; 23(2): 100-5.

20) Wilkin K, Slevin E. The meaning of caring to nurses: an investigation into the nature of caring work in an intensive care unit. Journal of Clinical Nursing. 2004; 13(1): 50-9. doi: 10.1111/j.1365-2702.2004.00814.x. PMID: 14687293.

21) Coyle MA. Meeting the needs of the family: the role of the specialist nurse in the management of brain death. Intensive Crit Care Nurs. 2000; 16(1): 45-50. doi: 10.1054/iccn.1999.1469. PMID: 10790714.

22) Dinmohammadi M, Hushmand A, Cheraghi M, Peyrovi H. Oppression in Nursing Profession and The Way of its Management. Journal of Hospital. 2013; 12(2): 81-90.

23) White G. Intensive care nurses' perceptions of brain death. Aust Crit Care. 2003; 16(1): 7-14. doi: 10.1016/S1036-7314(03)80023-1.

24) Corbin J, Strauss A. Basis of Qualitative Research. 3rd ed. Techniques and Procedures for Developing Grounded Theory. London: Sage Pub; 2008.

25) Burns N, Grove SK. The practice of nursing research Appraisal, Synthesis and Generation of evidence. 6th ed. USA: Saunders Elsevier; 2009.

26) Speziale HS, Streubert HJ, Carpenter DR. Qualitative research in nursing, advancing the humanistic imperative. Philadelphia: Lippincott Williams and Wilkins; 2011.

27) Burns N, Grove SK. The practice of nursing Research Conduct, Critique and Utilization. The University of Michigan: Elsevier/Saunders; 2002.

28) Elo S, Kyngas H. The qualitative content analysis process. J Adv Nurs. 2008; 62(1): 107-15. doi: 10.1111/j.1365-2648.2007.04569.x. PMID: 18352969.

29) Hsieh HF, Shannon SE. Three approaches to qualitative content analysis. Qual Health Res. 2005; 15(9): 1277-88. doi: 10.1177/1049732305276687. PMID: 16204405.

30) Krippendorff K. Content Analysis: An Introduction to Its Methodology. 2nd ed. Michigan: Sage; 2004.

31) Sandelowski M. Whatever happened to qualitative description? Research in Nursing and Health. 2000; 19: 114-23. doi: 10.1002/1098-240X(200008)23:4<334::AID-NUR9>3.0.CO;2-G.

32) Salehi SH, Kanani H, Abedi HA. Iranian nurses experiences of brain dead donors care in intensive care units: A phenomenological study. Iran J Nurs Midwifery Res. 2013; 18(6): 475-81. PMID: 24554946, PMCID: PMC3917131.

33) Forsberg A, Flodén A, Lennerling A, Karlsson V, Nilsson M, Fridh I. The core of after death care in relation to organ donation-A grounded theory study. Intensive Crit Care Nurs. 2014; 30(5): 275-82. doi: 10.1016/j.iccn.2014.06.002. PMID: 25042694.

34) Sadala M, Mendes H. Caring for organ donors: The intensive care unit nurses' view. Qualitative Health Research. 2000; 10(6): 788-805. doi: 10.1177/104973200129118822. PMID: 11146859.

35) Salahuddin N, Shafqat S, Mapara S, Khan S, Siddiqui S, Manasia R, et al. End of life in the intensive care unit: knowledge and practice of clinicians from Karachi, Pakistan. Intern Med J. 2008;38(5):307-13. doi: 10.1111/j.1445-5994.2007.01595.x, PMid: 18402559 
36) Mattiussi E, Berini A, Peressutti R, Bartolomeo SD. An observational study of Italian intensive care nurses' knowledge and attitudes towards organ donation and procurement. Organs, Tissues \& Cells. 2011; 14: 17782.

37) Carter-Gentry D, McCurren C. Organ procurement from the perspective of perioperative nurses. Aorn Journal. 2004; 80(3): 417-31. doi: 10.1016/S0001-2092(06)60535-8.

38) Hibbert M. Stressors experienced by nurses while caring for organ donors and their families. Heart \& Lung: The Journal of Acute and Critical Care. 1995; 24(5): 399-407. doi: 10.1016/S0147-9563(05)800627.

39) Pelletier-Hibbert M. Coping strategies used by nurses to deal with the care of organ donors and their families. Heart \& Lung. 1998; 27(4): 230-7. doi: 10.1016/S0147-9563(98)90034-6.

40) Yazdi moghaddam H, Pouresmaeili A, Manzari Z.S. Analysis of the reasons for nurses' confusion in relation to the concept of brain death from clinical and legal points of view. Electronic physician. $2018 ; 10$ (5), 6868-6876.

41) Floden A, Berg M, Forsberg A. ICU nurses' perceptions of responsibilities and organisation in relation to organ donation-a phenomenographic study. Intensive Crit Care Nurs. 2011; 27(6): 305-16. doi: 10.1016/j.iccn.2011.08.002. PMID: 21872472.

42) Long T, Sque M, Addington-Hall J. Conflict rationalisation: how family members cope with a diagnosis of brain stem death. Social science \& medicine. 2008; 67(2): 253-61. doi: 10.1016/j.socscimed.2008.03.039. PMID: 18442874.

43) Manzari ZS, Mohammadi E, Heydari A, Sharbaf HR, Azizi M, Khaleghi E. Exploring families' experiences of an organ donation request after brain death. Nursing Ethics. 2012; 19(5): 654-65. doi: 10.1177/0969733011423410. PMID: 22990425.

44) Smith Z, Leslie G, Wynaden D. Australian perioperative nurses' experiences of assisting in multi-organ procurement surgery: A grounded theory study. Int J Nurs Stud. 2015; 52(3): 705-15. doi: 10.1016/j.ijnurstu.2014.12.004. PMID: 25577305.

45) Karimi Moneghy H, Zubin F, Yavari M, Noghredani M, Abdollahi H. Nurses' Experience of Dealing With Dying Patients. The Journal of Urmia Nursing and Midwifery Faculty. 2013; 11(9): 688-97.

46) Fahidy F, Zeighami Mohamadi SH. Nurses attitude toward supportive work climate affecting transfer of learning to job. Iranian Journal Education of Medical Science. 2011; 11(2): 128-39. 